\title{
Severe facial fractures due to airbag deployment without utilization of a seat belt: A case report
}

\author{
Mahmoodreza ASHABYAMIN $^{1}$ (D), Fariba HAMDAMJO ${ }^{2}$ \\ ${ }^{1}$ Department of Plastic and Reconstructive Surgery, Shafa Hospital, Kerman University of Medical Sciences, Kerman, Iran. \\ ${ }^{2}$ Department of General Surgery, Bahonar Hospital, Kerman University of Medical Sciences, Kerman, Iran.
}

Corresponding Author: Mahmoodreza ASHABYAMIN

E-mail: mashabyamin@gmail.com

\begin{abstract}
This report is about a man of 25 years old $(175 \mathrm{~cm}, 90 \mathrm{~kg})$ who sustained bilateral Le fort I, II, and III fractures because of an inflating car airbag. Despite the fact that airbags harshly reduce both the mortality and morbidity from crashes as intercept frontal collisions, but with increasing use of airbags, increasing number of injuries caused by these devices is inevitable. Reports about serious injuries and even death due to airbag deployment highlight the necessity for a modification in design and speed of airbag deployment for accidents with various speeds.

Keywords: Airbag-mediated injury, Le fort fractures, Motor vehicle accident, Nasal defect
\end{abstract}

\section{INTRODUCTION}

Traffic accidents are one of the most important reasons for human injuries and deaths in many countries [1]. Strategies have been developed over the years to decrease the risk of death and serious injuries caused by motor vehicle accidents. Some of these useful strategies include speed limits, seat belt wearing, and use of airbags in vehicles. Although, there is no doubt that airbags decrease the risk of death and injury caused by motor vehicle accidents, airbag deployment injuries, including the head and neck injuries, have been broadly reported [2-4]. Le Fort fractures are those types of fractures in the face related to the maxillary bone and the surrounding structures in a usually horizontal and bilateral, transverse or pyramidal ways [5]. Here, we present a very rare case of three types of Le Fort fractures with closed fractures of mandible, condylar process, and nasal bones caused by airbag deployment. The patient was operated using open reduction internal fixation (ORIF) and nasal reconstruction surgery methods.

\section{CASE REPORT}

A 25-year-old man $(175 \mathrm{~cm}, 90 \mathrm{~kg})$ came to the emergency department approximately 1 hour after being involved in a motor vehicle crash. He did not fasten the seat belt while travelling at a high speed $(140 \mathrm{Km} / \mathrm{hr})$ and had an accident with a deviated car and frontal airbag deployed (Figure 1). Obvious fractures of the head and neck were detected on his plain radiographs (Figure 2). The patient was taken for computed tomography (CT) scan for more information when obvious fractures were detected (Figure 3).

The final diagnosis was bilateral Le fort I, II, and III fractures. In addition, closed fractures of mandible, condylar process, and nasal bones were detected on external examination using ICD-10 fracture codes [6]. After 4 days of hospitalization in the plastic and reconstructive surgery department, the patient was operated through ORIF surgery by using plates and screws (Figure 4). Also, after 4 months, nasal reconstruction surgery was performed for his nasal defects. Written informed consent was obtained from the patient for publication of individual information and photographs in an academic journal. 


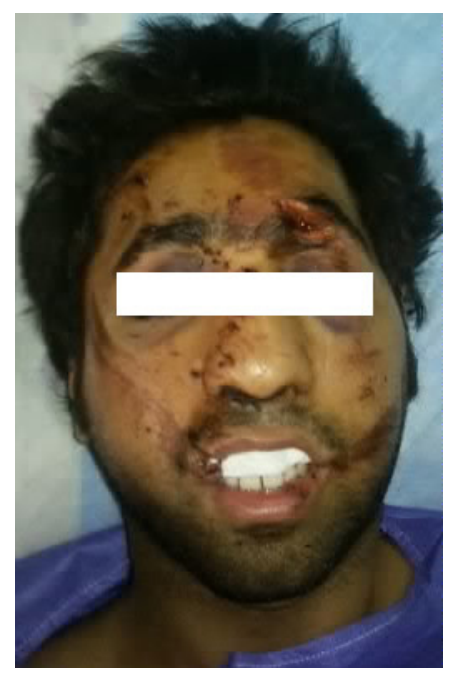

Figure 1. The patient before the surgery

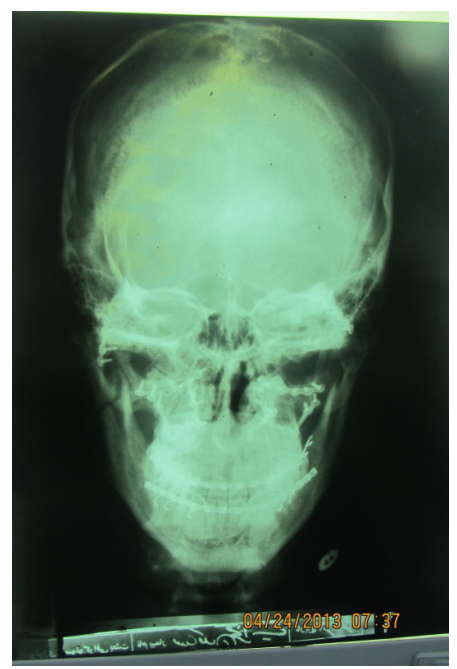

Figure 2. The head and neck radiography before the surgery

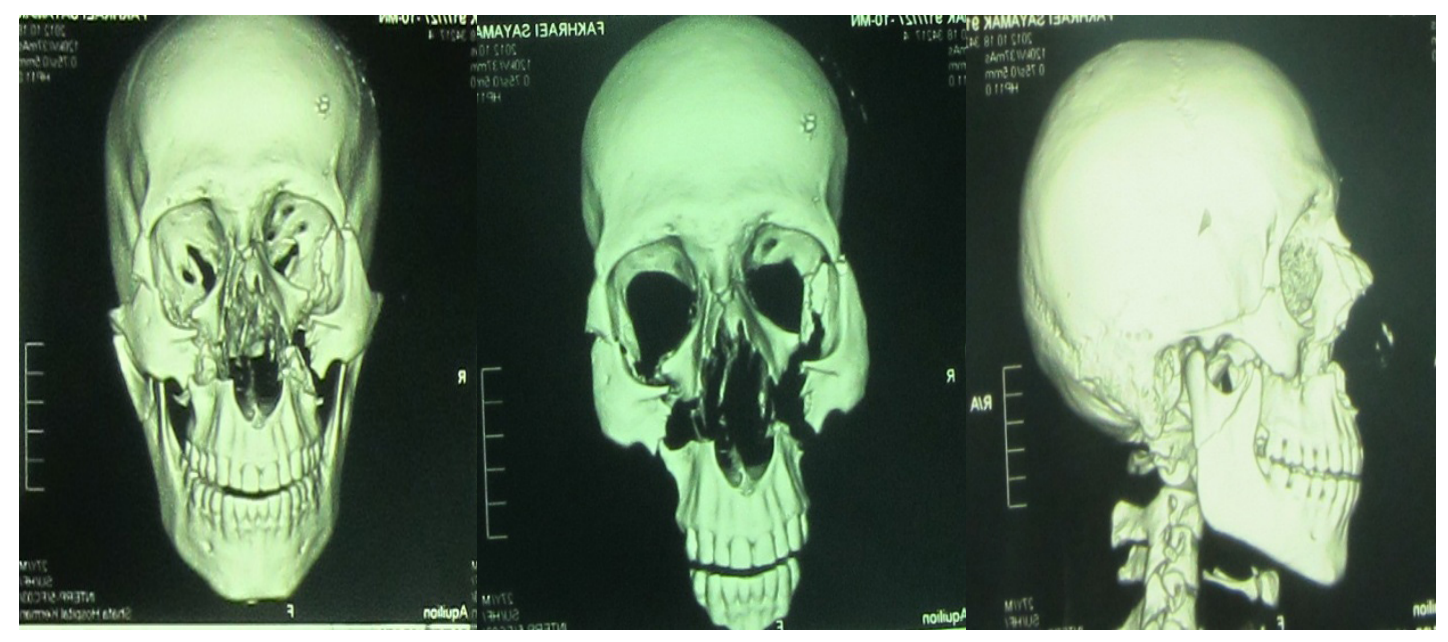

Figure 3. Pre-operation of the facial CT scans

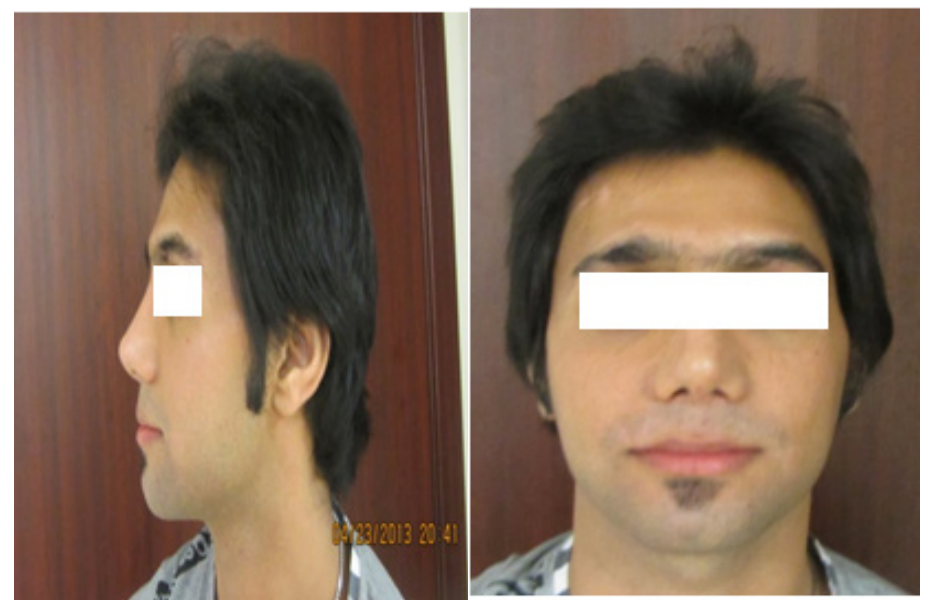

Figure 4. Six months after ORIF surgery and rhinoplasty 


\section{DISCUSSION}

Airbag was introduced in 1953 and became available in motor vehicles in 1973 [7]. The injuries caused by deploying airbags depend on pressure of the deployed airbag, accident severity and fastening the seat belt or not $[7,8]$. However, several researchers have shown that using airbags decrease mortality rate in most frontal crashes up to 20-30 percent [8]. In a frontal accident, airbag deployment and wearing a seatbelt reduced the risk of death by over $80 \%$ [9]. Yet, considerable evidence has shown that airbags can be as a source of morbidity and mortality in specific conditions. Moreover, with the increase in the use of vehicles equipped with airbags, injuries caused by airbags may occur more frequently. Therefore, more awareness about injuries caused by airbags can help solve this problem.

In the above-mentioned case, the driver had not worn the seat belt and consequently he was hit by the airbag full-force (Iranian vehicle: Samand Soren). In fact, since he did not fasten seat belt, he was thrown toward the deploying airbag. Therefore, such direct force caused the bilateral Le fort I, II, and III fractures and closed fracture of mandible and nasal bones. There are many reports about head injuries caused by airbags, such as facial trauma [4] and temporomandibular joint injury [3]. However, the present study reported one of the extensive injuries and fractures of head related to airbag deployment.

Not wearing seat belts when airbags deployed, hit by a lowpower airbag in comparison to hit by a powerful airbag, inflate unnecessarily in low speed crashes and moving children to the forward seats were described as some reasons that increased the suspicion of airbag related injuries [2,10-12]. Some other ways to reduce these damages include changing steering wheel to reduce the use of airbags in frontal accidents, use of educational programs to ensure the correct utilization of seat belts, and development of smart airbags.

In conclusion, it is necessary to know that the head and neck are exposed to risk more than other parts of the body in the frontal impacts resulting from airbag deployment (especially if a seat belt is not worn). Therefore, conducting researches is essential for improvement of airbag designs especially for prevention of the head and neck injuries.

\section{Compliance with Ethical Standards}

Written informed consent was obtained from the patient.

Finacial Support: The authors have no relevant financial information to disclose.

Conflict of Interest: The authors declare that they have no conflict of interests.

\section{Authors Contibutions:}

Study conception and design: M. A., Acquisition of data: M. A., Analysis and interpretation of data: M. A., Drafting of manuscript: M. A., F. H.

Critical revision: F. H. Both authors approved the final version of the article.

\section{REFERENCES}

[1] Marshall KW, Koch BL, Egelhoff JC. Air bag-related deathsand serious injuries in children: injury patterns and imaging findings. AJNR Am J Neuroradiol 1998; 19: 1599-607.

[2] Büyük Y, Üzün I, Erkol Z, Ağrıtmış H, Üstündağ KT. Air bagmediated fatal craniocervical trauma: a case report. Ulus Travma Acil Cerrahi Derg 2002;16:379-81.

[3] Levy Y, Hasson O, Zeltser R, et al. Temporo-mandibular joint derangement after air bag deployment: report of two cases. J Oral Maxillofac Surg 1998;56:1000-3. doi: 10.1016/s02782391(98)90667-x.

[4] Murphy RX, Birmingham KL, Okunski WJ, et al.The influence of airbag and restraining devices on the patterns of facial trauma in motor vehicle collisions. Plast Reconstr Surg 2000;105:516-20. doi: 10.1097/00006.534.200002000-00005.

[5] Allsop D, Kennett K. Skull and facial bone trauma. In: Nahum AM, Melvin J, eds. Accidental Injury: Biomechanics and Prevention. Berlin: Springer, 2008:254-8.

[6] ICD-10-CM Official Guidelines for Coding and Reporting 2014 available from: http://www.cdc.gov/nchs/data/icd/ icd10cm_guidelines_2014.pdf

[7] Yaremchuk K, Dobie RA. Otologic injuries from airbag deployment.Otolaryngol Head Neck Surg 2001;125:130-4. doi: $10.1067 / \mathrm{mhn} .2001 .117872$.

[8] Barry S, Ginpil S, O'Neill TJ. The effectiveness of air bags. Accid Anal Prev 1999;31:781-7.

[9] Crandall CS, Olson LM, Sklar DP. Mortality reduction with air bag and seat belt use in head-on passenger car collisions.Am J Epidemiol 2001;153:219-24. doi: 10.1093/aje/153.3.219.

[10] Khouzam RN, Al-Mawed S, Farah V, Mizeracki A. Nextgeneration airbags and the possibility of negative outcomes due to thoracic injury. Can J Cardiol 2014;30:396-404. doi: 10.1016/j.cjca.2014.01.002. Epub 2014 Jan 8.

[11] Jernigan M, Rath AL, Duma SM. Severe upper extremity injuries in frontal automobile crashes: the effects of depowered airbags. Am J Emerg Med 2005; 23: 99-105. doi:10.1016/j. ajem.2004.02.045

[12] Buckley G, Setchfield N, Frampton R. Two case reports of possible noise trauma after inflation of air bags in low speed car crashes. BMJ: British Medical Journal 1999;318(7182): 499. 